\title{
BREVES CONSIDERAÇÕES ACERCA DA PARTICIPAÇÃO DE CRIANÇAS E ADOLESCENTES EM PROCEDIMENTOS JUDICIAIS
}

\section{BRIEF CONSIDERATIONS ABOUT THE PARTICIPATION OF CHILDREN AND ADOLESCENTS IN JUDICIAL PROCEEDINGS}

\section{Enio Gentil Vieira Júnior ${ }^{1}$}

Resumo: Trata o presente artigo da produção legislativa e judicial relativa à garantia de participação de crianças e adolescentes em procedimentos que digam respeito aos seus interesses, considerando o paradigma aparentemente estatuído ao final da década de 1980 em que, teoricamente, promoveu os indivíduos antes considerados objeto de intervenção do mundo adulto à condição de sujeitos de direito. Observa-se que há pouca evolução neste sentido, aparentemente por ainda se pautarem as decisões por uma certa retórica tutelar. No entanto, observa-se que já há alguns mecanismos presentes na própria legislação que permitiram a discussão acerca da efetiva participação de crianças e adolescentes como protagonistas de processos judiciais.

Palavras-chave: Participação. Protagonismo. Criança e adolescente. Melhor interesse.

\begin{abstract}
The article is about the legislative and judicial provisions in the scope of children and adolescents participation in procedures that are of their interests, considering the paradigm apparently determined at the end of the eighties in which, theoretically, promoted individuals that were before considered object of intervention of the adult world to the entitlement of rights. It can be observed that there has been little development in this sense, apparently, because most rulings on the matter have shown a tendency of a tutelage. However, it can be perceived that some mechanisms already presented on legislation itself that may have permitted some discussion about the effective participation of children and adolescents as playing the main roles in judicial proceedings.
\end{abstract}

Keywords: Participation. Main roles. Children and Teenagers. Best Interest.

1 Advogado da infância e juventude e professor da Escola Superior da Magistratura do Estado de Santa Catarina (Esmesc) e da Escola Superior da Advocacia (ESA/ OABSC). Mestre em Direito pela Universidade Federal de Santa Catarina (UFSC). E-mail: eniogentil@tjsc.jus.br 


\section{INTRODUÇÃO}

Foi sob a vigência da legislação menorista, tutelar e assistencialista, anterior ao modelo de justiça da infância e juventude atualmente vigente, que até o segundo semestre do ano de 1990, há pouco mais de 27 anos, formou-se boa parte da comunidade jurídica brasileira. $\mathrm{O}$ primeiro grupo de profissionais formados sob a égide do Estatuto da Criança e do Adolescente, colou grau a partir da segunda metade da década de noventa, mas ainda sob forte influência do direito menoril.

Reconhece-se a falta de conhecimento suficiente de boa parte dos atores do sistema de justiça ainda hoje acerca do Estatuto da Criança e do Adolescente. Sua crítica estende-se aos Tribunais de Justiça, ainda apegados à figura do juiz de menores clássico:

A mudança da Doutrina da Situação Irregular para a da Proteção Integral ainda é, na maioria dos Juizados deste imenso país, de fachada. As Leis não mudam os atores jurídicos, ainda mais quando a grande maioria deles foi formada sem sequer abrir o ECA. Os cursos de Direito dedicam - e quando dedicam - uma disciplina, em regra optativa, para o estudo do Estatuto. Daí que os atores jurídicos não podem aplicar o que não conhecem. No âmbito dos Tribunais a situação é ainda mais grave. A grande maioria se formou, exerceu ou ouviu falar da postura paranoica do Juiz de Menores que, a partir de seu 'bom senso' escolhia o que era melhor para o adolescente, sem garantias processuais, sem advogado. (ROSA, 2007, p. 7).

Nesse sentido, é de se notar que a produção judicial do período seguinte ao Estatuto da Criança e do Adolescente, continua apegada a juízos moralistas. Veja-se:

E a estrutura se mantém. Basta um breve passar de olhos pela jurisprudência para se constatar que ainda existem referências ao 'menor que possui o direito de uma medida socioeducativa' ou ainda que 'o menor precisa ser encaminhado para os valores sociais'. Com estes se mostra impossível discutir porque estão alienados em sua bondade, 
acreditando sinceramente que estão fazendo o bem. Pura canalhice, incompatível com o Estado Democrático de Direito. (ROSA, 2007, p. 7).

A base ideológica dos profissionais alcunhados menoristas enrustidos, de base ideológica incompatível com a Doutrina da Proteção Integral, com decisões e forma de condução de processos permeados por uma espécie de bondade totalitária característica do trabalho dos atores do sistema de justiça da infância e juventude nos dias atuais. $\mathrm{O}$ resultado não é muito diferente daquele alcançado no âmbito da antiga justiça menorista, em que se deixa novamente de lado a autonomia do sujeito, criança ou adolescente, para que se lhe apliquem aquilo que acreditam os adultos ser bom (ROSA, 2007). Na mesma linha, verifica-se que ainda há decisões embasadas numa mentalidade retrógrada (PASSETTI et al., 1995).

O Estatuto da Criança e do Adolescente tem a relevante função, ao regulamentar o texto constitucional, de fazer com que este último não se constitua em letra morta. Contudo, a mera existência de leis que proclamem os direitos sociais, por si só, não muda as estruturas, antes há que se conjugar aos direitos uma política social eficaz, que de fato assegure materialmente os direitos já positivados (VERONESE, 2006).

Soma-se isto à falta de conhecimento do conteúdo do Estatuto da Criança e do Adolescente, que é interpretado sob a mesma lógica de outras legislações que se prestam a controle social, como o Código Penal (PASSETTI et al., 1995).

A arquitetura das funções do promotor de justiça nos procedimentos afetos à justiça da infância e juventude também pouco auxilia na construção de uma nova postura do sistema de justiça da infância e juventude. Exemplo é o procedimento de apuração de ato infracional, em que atuaria o Ministério Público como fiscal da lei ao mesmo tempo em que defendendo o interesse individual indisponível do adolescente ou interesse 
social representado pela exclusão do adolescente em conflito com a lei do convívio social (PASSETTI et al., 1995).

Ainda que o Estatuto da Criança e do Adolescente, por sua matriz constitucional, tenha estabelecido a necessidade de defensor em todo e qualquer processo que diga respeito a direito de crianças e adolescentes (PASSETTI et al., 1995), infelizmente ainda se insiste na desconsideração de um interesse manifesto de crianças e adolescentes.

Tal ausência de parâmetros de atuação, no entanto, não parece limitar-se às figuras da autoridade judiciária e do Ministério Público. O defensor, seja público, dativo ou constituído, na maior parte das vezes limita-se a função de cooperador da Justiça da Infância e Juventude, chancelando a vontade e atuação da autoridade judiciária e do Ministério Público. Não se coloca no processo na condição de porta-voz da criança e do adolescente, garantindo protagonismo processual e emancipação. Do contrário, torna-se porta-voz do juiz para com o destinatário da medida, como um mero intermediário. A participação mesmo da Defensoria Pública é inexpressiva, mantendo-se o defensor quase sempre calado ou requerendo, sem qualquer fundamento persuasivo (MINAHIM, 2010).

O papel do Juiz da Infância e da Juventude diz respeito, principalmente, à atuação processual deste magistrado, não possuindo poderes ilimitados, se comparado com a antiga figura do Juiz de Menores, devendo restringir sua atuação ao campo estritamente processual e desaparecendo figura protetora $\mathrm{e}$ repressora do pai de família, ficando em seu lugar, simplesmente, o Juiz de Direito, funcionando como órgão do controle jurisdicional do Estado (BRANCHER, 1999).

É de se notar, de forma a complementar o ensinamento acima, que o legislador, ao elaborar o Estatuto da Criança e do Adolescente confiou no bom preparo e nos bons propósitos de observá-lo - e de seguir seus princípios - por parte dos 
profissionais incumbidos de sua aplicação. Em razão disso, em diversos momentos reservou larga margem de liberdade/ discricionariedade aos seus operadores na ideia de que, assim, permitiria a melhor calibragem das ações e providências, em cada caso concreto, segundo as particularidades de cada situação (HESPANHOL; SOARES, 2006).

Sempre que, todavia, o bom preparo e os bons propósitos não se observam na prática, estes espaços de discricionariedade abrem margem a práticas antigarantistas, afrontadoras aos princípios da legalidade e do respeito ao devido processo legal (HESPANHOL; SOARES, 2006).

Nesse contexto, a formalização dos atos de um processo, com delineamento de um roteiro legal dando margens ao que pode e não pode ser feito pelo profissional em cada solenidade mostra-se uma importante estratégia garantidora da liberdade e dos demais direitos do cidadão cujo poder familiar esteja em discussão (HESPANHOL; SOARES, 2006).

No âmbito do Sistema de Justiça, a não efetividade e as dificuldades na garantia inclusive do direito de crianças e adolescentes serem ouvidos nos processos que lhes afetem, como vítima, testemunha ou como terceiro interessado, constitui-se como indicador seguro das limitações decorrentes da necessária transposição das práticas jurídicas que operam apenas parcialmente o modelo implementado pela Doutrina da Proteção Integral, que vincula o seu exercício à sua afirmação como sujeito de direitos (LEITE, 2000).

Também parece equivocado, a crença de que se poderia dar um novo conteúdo ao interesse superior, visto que o conceito é, sim, indeterminado e não deveria sequer constar do Estatuto da Criança e do Adolescente visto que a experiência histórica nos diz o quão perigoso é a utilização de conceitos desta natureza, com alta carga discricionária e subjetiva. 
Assim, quando Sanches (2014) e Melo (2011) atestam que o interesse superior não se oporia ao direito à participação, na prática, a invocação desde princípio é concretamente utilizada para afastar tal direito, assim como o contraditório e a ampla defesa nos procedimentos afetos à jurisdição da infância e juventude.

Cogita-se, inclusive que a própria deficiência técnica processual do Estatuto da Criança e do Adolescente tenha conduzido à prestação jurisdicional de aparência tutelar, visto que o próprio texto do Estatuto da Criança e do Adolescente contém elementos que permitem a subjetivação e discricionariedade na atuação do juiz.

Não é outro o posicionamento de Bordalho (apud MACIEL, 2011, p. 742-743):

Apesar de ser uma excelente lei, extremamente avançada, como veremos ao realizarmos o estudo de suas regras e realizadora de seus objetivos, o ECA peca em sua parte processual pela falta de técnica legislativa e pela má distribuição da ordem dos assuntos.

A falta de técnica do legislador estatutário fez com que determinadas pessoas passassem a crer que as regras processuais pudessem ser ignoradas e desrespeitadas, tudo sob a alegação de que estava sendo atendido o princípio do melhor interesse da criança e do adolescente, fazendo, ainda, com que grande parte dos operadores do Direito passasse a encarar o Estatuto da Criança e do Adolescente como uma lei de segunda categoria. De idêntico modo, passaram a ser adotados alguns entendimentos, como veremos em momento oportuno, totalmente descompassados de nosso sistema legal.

Ainda há a tendência de tudo se decide em nome da proteção integral, pouco importando a consideração das regras processuais, garantias e avanços no que se refere à questão da participação, ou protagonismo, de crianças e adolescentes em procedimentos que lhes digam respeito:

As mudanças previstas na concepção substituta custam, no entanto, em se ver de fato incorporadas à rotina dos atendi- 
mentos. As conquistas visíveis dizem mais com a mudança de linguagem do que propriamente com o aperfeiçoamento das práticas. Antes, tudo em nome do maior interesse, a essência da fundamentação. Agora, tudo em nome da proteção integral, um termo aparentemente mais sofisticado, mas que traz em si, em sentido literal, a mesma carga de discricionariedade e de subjetividade. Retórica por retórica, sobrevive a concepção do passado. Dentre as causas, a de que a cultura da Situação Irregular continua com lugar em nossos corações e mentes. Por isso, os pingos dos espirros da concepção menorista são possíveis de serem visualizados por todos os cantos. Se tivéssemos ao menos clareza acerca dos sintomas ou das sutilezas das manifestações desse paradigma sobrevivente! (Konzen, 2012, p. 88).

Assim, comparando-se a legislação pertinente ao Direito Menoril e a Legislação relativa ao Direito da Criança e do Adolescente, inegável que resta certa abertura ainda à discricionariedade da autoridade judiciária quando da aplicação da lei, o que permite o afastamento casuístico de certas garantias, em nome do melhor interesse ou da proteção integral, permitindo que se repita a antiga concepção tutelar.

Note-se que não se trata de princípio constante da redação original do Estatuto da Criança e do Adolescente, até porque havia uma certa resistência a tal instituto naquele período que findava a década de oitenta e iniciava a de noventa, visto que orientava toda a aplicação do direito do menor. É o que se pode observar das críticas formuladas por Beloff (2008, p. 15):

"Melhor interesse", "maior interesse", conforme o Decreto 99.710/90, "interesse superior", de acordo com o Estatuto da Criança e do Adolescente, as variações de "tradução" demonstram a vagueza desta diretriz e o perigo de funcionar como um "cheque em branco".

Da leitura de julgados de Tribunais de Justiça e dos Tribunais Superiores, fica bastante clara a preocupação de Mary Beloff, já que tal princípio, assim como o da proteção integral, acaba servindo como panaceia para todas as demandas que 
chegam à Justiça da Infância e Juventude.

O art. $8^{\circ}$ do Código de Menores de 1979, por seu turno, estabelecia que:

[...] a autoridade judiciária, além das medidas especiais previstas nesta lei [Código de Menores], poderá, através de portaria ou provimento, determinar outras de ordem geral, que, ao seu prudente arbítrio, se demonstrassem necessários à assistência, proteção e vigilância ao menor, respondendo por abuso ou desvio de poder. (BRASIL, 1979, p. 1).

Já o art. 87 da mesma lei, que dava amplos poderes à autoridade judiciária estabelecia “ [...] se a medida judicial a ser adotada não corresponder a procedimento previsto neste ou em outra lei, a autoridade judiciária poderá investigar livremente os fatos e ordenar, de ofício, as providencias". (BRASIL, 1979, p. 1).

Apesar da visível evolução, talvez revolução, do ponto de vista normativo, de uma legislação que arriscam chamar impecável, de referência, e a despeito da vasta produção acadêmica acerca do tema Direitos da Criança e do Adolescente, preocupa a produção judicial nesta área, aparentemente ainda apoiada numa lógica menorista, assistencialista, de negação de direitos, de retórica tutelar (SARAIVA, 2010), denominada doutrina da situação irregular.

A despeito do razoável arcabouço legal que sustenta o Direito da Criança e do Adolescente no Brasil, hoje com princípios regentes expressos na legislação (art. 100, parágrafo único, do Estatuto da Criança e do Adolescente), de procedimentos relativamente bem construídos em título próprio - que ocupa os arts. 152 a 224 e trata de sete procedimentos específicos -, de referências expressas ao contraditório (arts. 24, 101, $\S 2^{\circ}$ e 169 ) e ampla defesa (art. $101, \S 2^{\circ}$ ) como orientação em toda espécie de processo que diga respeito à demanda da Justiça da Infância e Juventude, a produção judicial, com alguma frequência negadora de direitos, ainda preocupa. 
$\mathrm{E}$, certamente, ponto que merece reflexão é o relacionado à participação e ao protagonismo de crianças e adolescentes em procedimentos judiciais que digam respeito a direitos seus, como os que tratam de colocação em família substituta, por exemplo, haja vista a inexistência de mecanismos concretos e atualizados à normativa internacional - para a efetivação da condição de sujeitos de direito na esfera processual.

\section{PROTAGONISMO PROCESSUAL COMO COROLÁRIO DO DIREITO À EXPRESSÃO}

Com a edição o Estatuto da Criança e do Adolescente, a participação da criança e do adolescente na família e na sociedade passa a ter conotação política bastante relevante, sintetizada no direito à liberdade, à manifestação de opinião e de expressão, dentre outras garantias fundamentais (DOXSEY, 1995).

No que tange à participação nos processos que digam respeito a direito de criança ou adolescente, o art. 100, parágrafo único, XII, cuja redação foi conferida pela Lei n. 12.010/09, prevê a oitiva obrigatória e participação como princípios regentes na aplicação das medidas previstas no Estatuto da Criança e do Adolescente.

De acordo com o mencionado dispositivo legal,

[...] a criança e o adolescente, em separado ou na companhia dos pais, de responsável ou de pessoa por si indicada, bem como os seus pais ou responsável, têm direito a ser ouvidos e a participar nos atos e na definição da medida de promoção dos direitos e de proteção, sendo sua opinião devidamente considerada pela autoridade judiciária competente, observado o disposto nos $\S \S 1^{\circ} \mathrm{e} 2^{\circ}$ do art. 28 desta Lei. (BRASIL, 1990a, p. 1).

Comparando-se com o direito processual civil vigente, que restringe até mesmo a presença de pessoas com menos de dezesseis anos como testemunhas em processos judiciais, o Estatuto da Criança e do Adolescente, no conjunto do ordenamento jurí- 
dico brasileiro, em tese, teria produzido uma verdadeira revolução nos conceitos de menoridade e maioridade, deixando ainda mais confusos os institutos da representação e assistência, e até mesmo da curatela ad litem que, como substituta da vontade do adolescente seria hoje dispensável, se observado do direito fundamental de opinião e de expressão (DOXSEY, 1995).

Por outro lado, considerando a normativa internacional, tal previsão não se trata exatamente de novidade, visto que o art. 12 da Convenção sobre os Direitos da Criança - Decreto ${ }^{\circ}$ 99.710/90-já estabelecida o direito da criança de ser ouvida e influenciar nos procedimentos judiciais que digam respeito a direitos seus. Veja-se:

1. Os Estados Partes assegurarão à criança que estiver capacitada a formular seus próprios juízos o direito de expressar suas opiniões livremente sobre todos os assuntos relacionados com a criança, levando-se devidamente em consideração essas opiniões, em função da idade e maturidade da criança.

2. Com tal propósito, se proporcionará à criança, em particular, a oportunidade de ser ouvida em todo processo judicial ou administrativo que afete a mesma, quer diretamente quer por intermédio de um representante ou órgão apropriado, em conformidade com as regras processuais da legislação nacional. (BRASIL, 1990b, p. 1).

Comentando este dispositivo legal, Melo (2011) ressalta que caberia aos adultos o esforço de garantir que o direito de crianças e adolescentes à expressão efetiva nos processos conforme critérios cognitivos e práticos. No mesmo sentido Sanches (2014, p. 487) indica que "[...] caberá aos adultos e às instituições desenvolverem as habilidades e competências para a promoção desse direito, com necessárias implicações procedimentais".

Dos comentários de Sanches e Melo podem-se destacar os seguintes desafios aos adultos atores do sistema de justiça: encontrar critérios cognitivos práticos para que permitam 
crianças e adolescentes se posicionarem, permitir a reversibilidade das escolhas feitas por crianças e adolescentes dentro do sistema e a adaptação dos procedimentos, considerando as peculiaridades das demandas relativas a este ramo do Direito.

O Estatuto da Criança e do Adolescente, tanto na sua redação original, como na resultante da reforma ocorrida em 2009 por meio da Lei n. 12.010, pode-se observar certo movimento, ainda que tímido, em favor da ouvida obrigatória de crianças e adolescentes, como, por exemplo, ocorre no procedimento de colocação em família substituta.

Sobre o conteúdo do art. $28, \S 1^{\circ}$, por exemplo, é bastante precisa a seguinte observação:

Os reflexos da nova lei sobre os dispositivos consagrados no código civil e de processo civil já se fazem sentir na condução das demandas de interesse do menor, mesmo que não se encontrem eles naquelas situações irregulares capituladas nos três incisos do art. 98 do Estatuto, dada a evidente assimilação pelo julgador das normas que enfatizam a consulta direta ao menor, segundo recomendações expressas na Lei 8.069/90, valendo citar o $\S 1^{\circ}$ do seu art. 28 dispondo que em termos de guarda, tutela e adoção "sempre que possível a criança e o adolescente deverá ser previamente ouvido e a sua opinião devidamente considerada". (DOXSEY, 1995, p. 98).

Já o Procedimento de Destituição do Poder Familiar traz no art. $161, \S 3^{\circ}$, que pode ser considerada norma adaptada ao comando do art. 12 da Convenção sobre os Direitos da Criança no que diz respeito à oportunidade de ouvida em processo judicial relativo à guarda: “[...] será obrigatória, desde que possível e razoável, a oitiva da criança ou adolescente, respeitado seu estágio de desenvolvimento e grau de compreensão sobre as implicações da medida" (BRASIL, 1990a, p.1).

Comparando-se ao Direito do Menor, por exemplo, não restam dúvidas de que se está diante de um paradigma abso- 
lutamente mais avançado, de efetiva titularidade de direitos humanos e protagonismo por parte de crianças e adolescentes.

Mas, pelo que se pode observar da produção judicial nacional, esta ideia de participação da criança - a exemplo do que também ocorre com a questão da (não) efetivação do contraditório e ampla defesa dos familiares requeridos em procedimentos de destituição do poder familiar - ainda não parece ter sido absorvida pelo Poder Judiciário, ao menos efetivamente.

Não é outro o entendimento de Melo (2011, p. 4):

Como a rápida promulgação da lei nacional para a adequação da Convenção, o país praticamente olvidou-se da própria norma internacional, deixando de lado seus princípios regentes - dentre os quais o de participação. Isto é inusitado em um país que reconhece o princípio da dignidade da pessoa humana como fundamento do Estado Democrático de Direito.

Doxsey (1995) considera que não se trata de mera faculdade, mas de necessidade, a participação de crianças e adolescentes nos processos judiciais que lhes digam respeito, considerando a idade de doze anos, por exemplo - quando se torna o indivíduo adolescente na dicção do art. $2^{\circ}$ do Estatuto da Criança e do Adolescente - como a "idade piso" para consulta acerca da colocação em família substituta na modalidade adoção.

No que tange à participação nos processos que digam respeito a direito de criança ou adolescente, dispositivo de grande relevância previsto no Estatuto da Criança e do Adolescente, o art. 100, parágrafo único, XII, que teve redação conferida pela Lei n. 12.010/09, prevê a oitiva obrigatória e participação de crianças como princípio regente na aplicação das medidas previstas no Estatuto da Criança e do Adolescente.

Ainda no que tange ao aspecto do acesso à justiça, garantido a toda criança ou adolescente (art. 141, parágrafo único), inclusive quando seus interesses estiverem em conflito com os 
de seus representantes legais (art. 142, parágrafo único), pode-se dizer que há evidente necessidade de se rediscutirem os limites da capacidade postulatória.

Doxsey (1995, p. 98), lança o seguinte questionamento: "[...] podem os nossos jovens absoluta ou relativamente incapazes, acionarem a Justiça, contra os seus pais, tutores, curadores, inclusive?"

O que se observa na prática é que sequer se dá a oportunidade de registrar a opinião da criança e do adolescente em juízo, sendo sua opinião cabalmente desconsiderada quando, no máximo, poderia o juiz, depois de ouvi-lo, afastá-la fundamentadamente.

Veja-se o seguinte julgado do Tribunal de Justiça do Estado de Minas Gerais:

A oitiva do menor não é imprescindível para a decisão sobre quem lhe terá a guarda, sendo, ao contrário, desaconselhável em muitos casos, dada a evidente pressão psicológica a que é então submetida a criança, da mesma forma que, em virtude da prevalência do interesse e do bem-estar do menor, não pode ele ficar sujeito a sucessivas buscas e apreensões, a pretexto de cumprimento de formalidades. (MINAS GERAIS, 1993, p. 1).

No mais, algumas indagações surgem interessantes, como a de que seria "[...] interessante notar que a criança que comparece ao processo solicitando a sua oitiva não é parte interveniente no processo, pelo que não poderá recorrer dessa decisão em hipótese de ver indeferida essa sua pretensão" (Leite, 2000, p. 36).

A propósito, não há previsão em nosso ordenamento jurídico que permita à criança e ao adolescente recorrerem autonomamente de decisões judiciais que digam respeito a interesses seus, dependendo, sempre, da iniciativa de seus responsáveis legais, da Defensoria Pública ou do Ministério Público, estes dois últimos, como se tratará adiante, ainda polemizando acer- 
ca da titularidade e da condição de curador especial.

Assim, ao menos aparentemente, a festejada condição de sujeito plenos de direito que se conferiu a crianças e adolescentes pelo Direito da Criança e do Adolescente não se acomodou ainda ao sistema de justiça previsto na Lei n. 8.069/1990, afinal, do ponto de vista da capacidade postulatória e do direito à liberdade e a expressão em nível judicial, estes sujeitos ainda acabam como objeto de tutela.

Melo (2012) vai um pouco mais longe na crítica ao modelo estabelecido pela legislação brasileira, cuja perspectiva classifica como adultocêntrica, ressaltando a necessidade do reconhecimento das competências jurídicas de crianças e adolescentes.

Também discutível o conceito de sujeito de direitos em face do conceito de pleno domínio de direitos:

Toda a reflexão sobre o papel da criança na atual sociedade se choca contra uma contradição inerente à noção mesma de 'infância'. A criança não é um cidadão com pleno domínio de seus direitos, mas já é um sujeito de direito, uma 'pequena pessoa'.

Reconhecer à criança o direito de palavra, o direito de ser ouvida e de se manifestar em juízo corresponde, "colocando-se numa perspectiva ética mais larga, a reconhecer a humanidade do Homem (e) colocando-se no contexto da luta pelos direitos do Homem, a reconhece que estes existem antes dos 18 anos. [...]

A ideia da 'oitiva' de uma criança em juízo faria tremer um pai pater famílias, porque só ela fazia reinar a ordem em sua casa. Reconhecer à criança os meios de defender sua causa, permite-se-lhe conquistar o espaço de liberdade ao qual ela tem direito, apesar e em consideração de sua idade. (Leite, 2000, p. 23-24).

A despeito das críticas e deficiências do sistema de justiça aplicado no Estatuto da Criança e do Adolescente sobre a oitiva de crianças e adolescentes em seus respectivos processos, claro fica que em termos princípiológicos, o Direito da Criança 
e do Adolescente - que antecede e vai além da própria Lei n. 8.069/90 - atribui ao sistema de justiça a tarefa de se adaptar para a ouvida de crianças e adolescentes em razão da condição de sujeitos de direito que são.

\section{INSTRUMENTALIZAÇÃO DO DIREITO À PARTICIPAÇÃO}

Para Sanches (2014, p. 477), a não efetividade do direito de crianças e adolescentes serem ouvidos nos procedimentos judiciais trata-se de indicador de que apenas parcialmente a doutrina da proteção integral vem integrando a prática jurídica:

No âmbito do Sistema de Justiça, a não efetividade e as dificuldades na garantia do direito de crianças e adolescentes serem ouvidos nos processos que lhes afetem, como vítima, testemunha ou como terceiro interessado, constitui-se como indicador seguro das limitações decorrentes da necessária transposição das práticas jurídicas que operam apenas parcialmente o modelo implementado pela Doutrina da Proteção Integral, que vincula o seu exercício à sua afirmação como sujeito de direitos.

Melo (2010, p. 46), falando especificamente de crianças e adolescentes em situação de rua, critica a postura de não reconhecimento das suas competências subjetivas e jurídicas. Veja-se:

Não podemos efetivamente falar em direitos humanos de crianças e adolescentes, e particularmente daqueles em situação de rua, se não pensarmos no reconhecimento de suas competências, subjetivas e jurídicas, para que possam assumir posições jurídicas na sociedade. Trata-se de condição inerente ao novo paradigma de titularidade de direitos humanos por crianças e adolescentes.

A não ser que ainda se considere estar o sistema informalmente pautado por um modelo tutelar, desconhecedor das competências subjetivas e jurídicas de crianças e adolescentes, não parece justificar o seguimento de elevado número de procedi- 
mentos sem que se tenha permitido aos principais interessados em seu desfecho - crianças e adolescentes - a participação efetiva e o mínimo de influência na decisão judicial que trata de medida tão drástica em suas vidas.

O Comitê dos Direitos da Criança das Nações Unidas, no Comentário Geral n. 12, considera que a aplicação do direito de ser ouvido exige cinco etapas, que deveriam ser consideradas na legislação relativa à justiça da infância e juventude, assim como na legislação de organização judiciária local (ONU, 2014).

\subsection{Fase preparatória}

$\mathrm{Na}$ fase preparatória, recomenda-se que seja assegurado à criança o conhecimento de seus direitos e sobre o impacto de suas opiniões no provimento judicial. Nessa ocasião, a criança também deve ser informada de que pode participar diretamente (como a autodefesa do adolescente em conflito com a lei), ou por meio de representante legal. Finalmente, nesse caso, deve ser esclarecido à criança ou adolescente o papel de cada ator do sistema de justiça.

O reconhecimento de crianças e adolescentes como sujeitos de direito demanda a superação de ainda viva concepção inquisitória, e, por conseguinte, o giro fundamental se traduz na prática com a presença do defensor público ou advogado constituído como garantia do devido processo legal (divisão de funções judiciais e processuais).

No art. 142, parágrafo único, do Estatuto da Criança e do Adolescente, ademais, há expressa previsão de nomeação de curador especial para quando houver conflito entre os interesses da criança ou adolescente destinatário de uma intervenção judicial e os de seus responsáveis legais.

A lei, assim, apesar de não estimular, não possui mecanismos que impeçam que à criança ou adolescente em relação ao qual haja procedimento tramitando na Justiça da Infância 
demandando direito que lhe diga respeito, tenha advogado nomeado para representação se seus próprios interesses.

Em tais situações, quando muito, têm sido invocada a figura do curador especial, em que, oferecendo defesas formais, meramente legitimadoras da atuação do Representante do Ministério Público e da autoridade judiciária, advogados atuam como colaboradores, ou cooperadores, do sistema de justiça.

Bordalho (apud MACIEL, 2011, p. 738), critica o descuido do legislador ao tratar da questão do curador especial, considerando, inclusive, a expressão inadequada. Veja-se:

A doutrina não deu a atenção devida a este artigo, havendo uma limitação em mencionar que há a possibilidade de nomeação de curador especial, mesmo que algum dos responsáveis venha a ser encontrado posteriormente e que trata-se de uma garantia para crianças e adolescentes. Porém, não se cuidou de analisar a natureza de sua nomeação e sobre quem a mesma cairá, já que não se trata, como dito acima, de curadoria especial, na técnica da expressão, motivo pelo qual não mais a utilizaremos.

A figura do advogado, considerada indispensável à administração da justiça pela Constituição de 1988 (art. 133) tem tratamento especial no art. 206 do Estatuto da Criança e do Adolescente, que estabelece que a criança ou o adolescente, poderão intervir nos procedimentos de que trata esta Lei, através de advogado.

Houve, portanto, considerável avanço em distinguir, de certo modo, a figura da defesa à criança ou adolescentes, seus pais ou responsável e, ainda, qualquer pessoa que tenha legítimo interesse, reforçando certa autonomia da titularidade dos direitos dos destinatários dos regramentos previstos no Estatuto da Criança e do Adolescente.

Nada impede, assim, que à criança ou adolescente em relação ao qual haja procedimento tramitando na Justiça da Infân- 
cia demandando direito que lhe diga respeito, tenha advogado nomeado para representação se seus próprios interesses. Especificamente em relação ao adolescente em conflito com a lei, há regra expressa determinando que jamais haverá processo sem defensor. É o comando do art. 207.

Atualmente, o Código de Processo Civil prevê expressamente a função da curadoria especial como pertencente à Defensoria Pública (art. 72, parágrafo único da Lei n. 13.105/15), o que afasta a discussão acerca do órgão legitimado para tal.

No entender de Dexsey (1995, p. 98):

A instituição da curadoria ad litem (art. $9^{\circ}$, do CPC) para o incapaz carente de representação legal ou com interesses conflitantes com os seus representantes, passar por uma reformulação, na medida em que o Curador assim designado, ao invés de substituir a vontade do menor, põe-se ao seu lado, tornando-se verdadeiro porta-voz de seu interesse.

No mais, não há como se falar em figura do curador especial hoje no direito da criança e do adolescente sem que se considere o direito à expressão e opinião, ou, mais especificamente, o direito à participação efetiva no processo judicial, que pode ter neste instituto seu porta-voz.

\subsection{Audiência}

O comentário Geral n. 12 chama a atenção para o fato de que o ambiente construído deve ser facilitador e encorajador, para que a criança possa ter a certeza de que o adulto responsável pela audição está disposto a ouvir e a considerar seriamente o que a criança decidiu comunicar.

\subsection{Avaliação da capacidade da criança}

Considerando a condição peculiar de pessoa em desenvolvimento, e não mero incapaz, verificando que a criança ou adolescente é capaz de formar seus próprios pontos de vista de uma maneira razoável e independente, a autoridade judiciária 
deve considerar suas opiniões como um fator significativo na resolução de questões.

Já o Conanda (2014, p. 1) recomenda que "[...] quando manifestarem o desejo de serem ouvidos em procedimento judicial, recomenda-se que a criança e o adolescente sejam previa e adequadamente informados de seus direitos por equipe interprofissional ou multidisciplinar".

\subsection{Informações sobre o peso dado às opiniões da criança}

A autoridade judiciária deve informar a criança ou o adolescente sobre o resultado do processo e explicar como suas opiniões foram consideradas, permitindo que a criança ou o adolescente possa decidir sobre interpor recurso ou reclamação.

Nesse sentido, o atendimento pelo sistema de justiça deverá proporcionar à criança e ao adolescente a escolha e a oportunidade de expressar livremente suas opiniões e demandas sobre os assuntos a eles relacionados, levando-se em consideração os fatores idade, maturidade e interesse (CONANDA, 2014).

\subsection{Reclamações e vias de recurso}

Basicamente, o Comentário Geral n. 12 garante que crianças e adolescente insurjam-se quando não lhes é garantido o direito a ser ouvido e de expressar sua opinião. Já o Conselho Nacional dos Direitos da Criança e do Adolescente estabelece:

[...] será garantido o direito da criança e do adolescente a efetiva participação e a expressão de suas opiniões e demandas nos procedimentos que impliquem na construção de planos individuais de atendimento e nas ações para superar situações de risco ou vulnerabilidade. (CONANDA, 2014, p. 1).

Assim, considerando - e comparando - as recomendações das Nações Unidas acerca da participação de crianças em processos judiciais e a realidade que se verifica da própria legislação nacional e da produção judicial, observa-se que, apesar de haver ainda um certo caminho a se trilhar, já há algum aparato 
normativo a servir de referência aos atores do sistema de justiça.

Considerando o modelo ideal das Nações Unidas, não se pode dizer que, no sistema de justiça da infância brasileiro, crianças e adolescente participam efetivamente de seus procedimentos, continuando na condição de meros destinatários - ou objetos - de intervenções judiciais.

\section{CONCLUSÃO}

Em conclusão ao presente estudo, pode-se observar que, em certa medida, apesar da mudança clara e declarada entre a doutrina da situação irregular, orientadora do Direito do Menor, e a doutrina da proteção integral, fundante do Direito da Criança e do Adolescente e de que o Estatuto da Criança e do Adolescente expressamente dispõe, nota-se ainda pouca diferença entre modelo de prestação jurisdicional atual e aquele relativo à justiça de menores.

No entanto, a simples leitura da Lei n 8.069/1990 demonstra que não há qualquer elemento objetivo que estabeleça que outros direitos ou garantias, inclusive de ordem processual, poderiam ser afastados em nome de supostos interesses da criança ou adolescente.

Desse modo, apesar de haver certo consenso tanto na produção acadêmica como na jurisprudência acerca da ruptura estabelecida pela superação da doutrina da situação irregular pela doutrina da proteção integral, causa estranheza, num primeiro momento, que ainda haja tanta semelhança na produção judicial, à desconsideração da efetiva condição de crianças e adolescentes como sujeitos de direitos, com possibilidade, em tese, de influenciar nas decisões, com sentenças pautadas por fundamentação geral no melhor interesse e não em regramentos objetivos constantes da lei e, finalmente, com absoluta desconsideração do princípio do contraditório, em suma, tendendo, ainda, à sumarização e à simplicidade procedimental. 
Curioso é o fato do Estatuto da Criança e do Adolescente, conforme já mencionado, pautado pela doutrina da proteção integral, cumpre, aparentemente, a função de garantir a crianças e adolescentes a condição de sujeitos efetivos de seus direitos, inclusive com possibilidade de participação em processos judiciais que lhes digam respeito, tratados no art. 100, parágrafo único, XII, como direito à oitiva e participação.

Sobre uma certa insistência na simplicidade procedimental, característica formalmente assumida pela legislação menoril e aparentemente rechaçada pela legislação relativa ao Direito da Criança e do Adolescente, que conta com procedimentos relativamente sofisticados e adaptados às especiais demandas relativas a violações de direitos de crianças e adolescentes, quando suscitados, os atores do sistema de justiça tendem à sumarização e simplificação em detrimento aos regramentos processuais fundamentais, como a obrigatória nomeação de curador especial, por exemplo.

Quanto à obrigatoriedade da presença da defesa nos procedimentos da jurisdição da infância e juventude, previsto expressamente no art. 206, além de garantia a todos, crianças, adolescentes e adultos, em nível constitucional, ainda há certa resistência à figura da defesa como forma de garantir igualdade na relação processual, preferindo-se, como regra, a ideia de que as decisões judiciais deveriam representar uma "posição de consenso", preferindo-se a defesa cooperativa, ou figurativa, e não combativa.

Há quem considere, igualmente, existir no atual modelo uma ideia de superior interesse baseado em normas objetivas, e não mais o velho melhor interesse do direito menorista, baseado agora em normas objetivas, finalísticas, voltadas à proteção integral, tendo a prática, no entanto, demonstrado que a aplicação do instituto não passa de uma repetição do modelo anterior em nível jurisdicional, servindo, palavras de Tânia da Silva Pereira, 
como um cheque em branco para a autoridade judiciária.

Finalmente, não se verifica a efetiva garantia à participação de crianças e adolescentes nos processos em que seus direitos estejam em discussão, a despeito de expressa previsão legal.

Claro, comparando-se ao Direito do Menor, não resta dúvida de que se está diante de um paradigma mais qualificado de prestação jurisdicional, de efetiva titularidade de direitos humanos e protagonismo por parte de crianças e adolescentes, mas, é inegável que em nível judicial crianças e adolescentes ainda não figurem como cidadãos plenos de direito.

A tarefa dada ao legislador pela doutrina da proteção integral, de aperfeiçoar o sistema de justiça à condição de crianças e adolescente como sujeitos de direito, garantido a sua ouvida em procedimentos judiciais em um nível capaz de influenciá-las, ainda não se efetivou.

Com isso, a notícia que este breve estudo talvez possa dar aos atores do sistema de justiça é de que conceder a alguém a condição de sujeito de direitos deve ultrapassar o nível da promessa, propósito ou ensaio normativo inconsequente, mas necessita significar efetividade, proteção jurídica de fato e de direito, assim como a tarefa árdua e diária de permitir que crianças e adolescentes figurem como efetivos protagonistas de seus processos judiciais.

\section{REFERÊNCIAS}

BELOFF, Mary. Los derechos del niño enel sistema interamericano. Ciudad Antónoma de Buenos Aires: Del Puerto, 2008.

BRANCHER, Naiara. O Estatuto da Criança e do Adolescente e o novo papel do Poder Judiciário. In: PEREIRA, Tânia da Silva (Coord.). O melhor interesse da criança: um debate interdisciplinar. Rio de Janeiro: Renovar, 1999.

BRASIL. Casa Civil. Lei n. 6.697, de 10 de outubro de 1979. Institui o Código de Menores. Disponível em: <http://www.planalto.gov.br/ccivil_03/leis/1970-1979/L6697. htm>. Acesso em: 20 maio. 2017.

BRASIL. Casa Civil. Lei n. 8.069, de 13 de julho de 1990a. Dispõe sobre o Estatuto 
da Criança e do Adolescente e dá outras providências. Disponível em: <http://www. planalto.gov.br/ccivil_03/leis/18069.htm>. Acesso em: 20 maio. 2017.

BRASIL. Casa Civil. Decreto n. 99.710, de 21 de novembro de 1990b. Promulga a Convenção sobre os Direitos da Criança. Disponível em: <http://www.planalto.gov.br/ ccivil_03/decreto/1990-1994/d99710.htm>. Acesso em: 20 maio. 2017.

CONANDA-Conselho Nacional dos Direitos da Criança e do Adolescente. Resolução n. 169, de 13 de novembro de 2014. Dispõe sobre a proteção dos direitos de crianças e adolescentes em atendimento por órgãos e entidades do Sistema de Garantia de Direitos, em conformidade com a política nacional de atendimento da criança e do adolescente prevista nos arts. 86, 87, incisos I, III, V e VI e 88, da Lei $n^{\circ} 8.069$, de 13 de julho de 1990. Disponível em: <dh.sdh.gov.br/download/resolucoes-conanda/res-169.pdf>. Acesso em: 23 maio 2017.

DOXSEY, Sônia Maria Rabelo. A participação da criança e do adolescente no processo. Revista de Processo, São Paulo, v. 20, n. 78, p. 97-100, 1995.

HESPANHOL, André; SOARES, Francisca de Assis. A oitiva informal e o respeito aos princípios do contraditório e da ampla defesa. In: FRASSETO, Flávio Américo (Org.). Apuração de ato infracional e execução de medida socioeducativa: considerações sobre a defesa técnica de adolescentes. São Paulo: ANCED, 2006. p. 91-113.

KONZEN, Afonso Armando. Fundamentos do Sistema de Proteção da Criança e do Adolescente. Revista do Ministério Público do RS, Porto Alegre, n. 71, p. 85-11, jan./ abr. 2012.

LEITE, Eduardo Oliveira. A oitiva de crianças nos processos de família. Revista Jurídica, Porto Alegre, v. 48, n. 278, p. 22-38, 2000.

MACIEL, Kátia Regina Ferreira Lobo Andrade. Curso de direito da criança e do adolescente: aspectos teóricos e práticos. Rio de Janeiro: Editora Lumen Júris, 2011.

MELO, Eduardo Rezende. Criança e adolescentes em situação de rua: direitos humanos e justiça. São Paulo: Malheiros, 2011.

MENDEZ, Emílio Garcia; COSTA, Antônio Carlos Gomes da. Das necessidades aos direitos. São Paulo: Malheiros, 1994

Minahim, Maria Auxiliadora. Série Pensando o Direito: Responsabilidade e Garantias ao adolescente autor de ato infracional. Salvador/Brasília: PNUD (Coord.),2010.

MINAS GERAIS - TJMG.Ap. 5.253-0/90.349-1, Cambuí - Rel. Paulo Tinôco. $1^{\mathrm{a}}$ Câmara Cível - publicação em: 6/10/93. Disponível em: <http://www.apase.org.br/ 83005-oitivamernor.htm>. Acesso em: 23 maio 2017.

ONU-Organização das Nações Unidas. Comentário Geral n. 12, de 12 de julho de 2009. The right of the child to be heard. Disponível em: <http:/www2.ohchr.org/english/bodies/crc/docs/AdvanceVersions/CRC-C-GC-12.pdf>. Acesso em: 23 maio 2017.

PASSETTI, Edson et al. Violentados: crianças, adolescentes, justiça. São Paulo: Imaginário, 1995.

PEREIRA, Tânia da Silva (Coord). O melhor interesse da criança: um debate interdisciplinar. Rio de Janeiro: Renovar, 1998.

RAMIDOFF, Mário Luiz. Direito da criança e do adolescente: teoria jurídica da prote- 
ção integral. Curitiba: Vicentina, 2008.

ROSA, Alexandre Morais da. Introdução crítica ao ato infracional: princípios e garantias. Constitucionais. Rio de Janeiro: Lumen Juris, 2007.

SANCHES, Helen Crystine Corrêa. Da Vara de Menores à Vara da Infância e Juventude: Desafios para a Proteção Integral dos Direitos de Crianças e Adolescentes no Sistema de Justiça Brasileiro.Tese (Doutorado em Direito)- UFSC, Florianópolis, 2014.

SARAIVA, João Batista da Costa. Direito penal juvenil: adolescente e ato infracional. Garantias processuais e medidas socioeducativas. 4. ed. Porto Alegre: Livraria do Advogado, 2010.

VERONESE, Josiane Rose Petry. Direito da criança e do adolescente. v. 5. Florianópolis: OAB/SC Editora, 2006. (Coleção Resumos Jurídicos).

Artigo recebido em: 30/05/2017

Artigo aprovado em: 06/10/2017 